\title{
HERista
}

\section{Fatores determinantes no atendimento a vítima de parada cardiorrespiratória pelos serviços pré-hospitalar}

\author{
Determining factors in the care of victims of cardiorrespiratory stop for
}

pre-hospital services

Patrícia de Oliveira Lima Sirleide Corrêa Range Flávia Lima Miranda Carliaine Aparecida Siqueira ${ }^{2}$ Herlon Fernandes de Almeida Marcos Luciano Pimenta Pinheiro

Leticia Neves Vieira Costa ${ }^{4}$ Geisa Sereno Velloso da Silva ${ }^{1}$

${ }^{1}$ Hospital Universitário da Universidade Federal de Juiz de Fora/Empresa Brasileira de Serviços Hospitalares, Brasil.

${ }^{2}$ Departamento de Enfermagem, Universidade Fderal dos Vales do Jequitinhonha e Mucuri, Brasil.

${ }^{3}$ Departamento de Ciências Básicas, Universidade Federal dos Vales do Jequitinhonha e Mucuri, Brasil.

${ }^{4}$ Hospital Sofia Feldman, Universidade Federal de Minas Gerais, Brasil.

\section{\atrícia Lima}

Rua Dr. Osmar Silva, 155, Bom Pastor, Juiz de Fora, Minas Gerais CEP: $36021-080$

७ patricia.enfermeiraobstreta@gmail.com

\section{RESUMO}

Introdução: Mesmo com avanços nos últimos anos relacionados à prevenção e ao treinamento de manobras de reanimação cardiopulmonar, ainda ocorrem muitos óbitos por parada cardiorrespiratória, sendo que as doenças cardiovasculares são a principal causa de mortalidade e incapacidade no Brasil e no mundo. Objetivo: Analisar as publicações referentes aos fatores determinantes na qualidade do atendimento a vítimas de parada cardiorrespiratória no ambiente pré-hospitalar. Material e Métodos: Revisão de literatura com o objetivo de responder à questão: quais os fatores determinantes na qualidade do atendimento a vítimas de parada cardiorrespiratória no ambiente pré-hospitalar? Como estratégia de busca utilizou-se publicações de 2008 a 2016, encontradas nas bases de dados Índice Bibliográfico Espanhol de Ciências da Saúde, Medical Literature Analysis and Retrieval System Online, portal Google Acadêmico, Scientific Electronic Library Online e Literatura Latino-Americana e do Caribe em Ciências da Saúde. Resultados: Foram identificados 2096 artigos e, após análise dos critérios de elegibilidade, foram selecionados 14 estudos. Os estudos foram classificados dentre os extratos da produção intelectual, obtendo-se: $43 \%$ como nível de evidência 5, 36\% com nível de evidência 4 e $21 \%$ com nível 3. Não foram identificados estudos com nível de evidência 2 ou 1. Após análise de evidência, houve a identificação e distribuição dos fatores que interferem na qualidade do atendimento a vítima de parada cardiorrespiratória em 4 categorias: I- estrutura física, recursos humanos, materiais e equipamentos; II- organização dos procedimentos e agentes estressores; III- sentimentos, emoções e alterações físicas dos profissionais envolvidos; IV- conhecimento técnico/prático da equipe. Conclusão: Por meio desta revisão pode-se identificar os fatores determinantes no atendimento a vítima de parada cardiorrespiratória no ambiente préhospitalar. Além disso, espera-se oferecer subsídio na atualização de protocolos assistenciais, assim como ressaltar a necessidade de educação permanente das equipes, adequação e gerenciamento de recursos humanos e materiais, proporcionando um atendimento eficaz e de qualidade.

Palavras-chave: Serviços Médicos de Emergência; Parada Cardíaca; Qualidade da Assistência à Saúde.

\section{ABSTRACT}

Introduction: Despite advances in recent years related to the prevention and training of cardiopulmonary resuscitation maneuvers, there are still many deaths due to cardiopulmonary arrest, with cardiovascular diseases being the main cause of mortality and disability in Brazil and in the world. Objective: To analyze the publications regarding the determinants of the quality of care for victims of cardiorespiratory arrest in the prehospital setting. Material and Methods: Literature review with the objective of answering the question: What are the determining factors in the quality of care for the victims of cardiorespiratory arrest in the prehospital environment? As a search strategy, we used publications from 2008 to 2016, published in the databases Índice Bibliográfico Espanhol de Ciências da Saúde, Medical Literature Analysis and Retrieval System Online, portal Google Acadêmico, Scientific Electronic Library Online e Literatura Latino-Americana e do Caribe em Ciências da Saúde. Results: A total of 2096 articles were identified that, after analysis of the eligibility criteria, 14 studies were selected. The studies were classified among the extracts of the intellectual production, obtaining: $43 \%$ as evidence level 5, 36\% with evidence level 4 and $21 \%$ with level 3 . No studies with evidence level 2 or 1 were identified. After analysis of evidence, there were the identification and distribution of factors that interfere in the quality of care of the victim of cardiorespiratory arrest in four categories: I - physical structure, human resources, materials and equipment; II- organization of procedures and stressors; III feelings, emotions and physical changes of the professionals involved; IV- technical / practical knowledge of the team. Conclusion: Through this review we can identify the determining factors in the care of the victim of cardiorespiratory arrest in the prehospital environment. In addition, it is hoped to offer subsidy in the updating of assistance protocols, as well as to emphasize the need for permanent education of the teams, adequacy and management of human and material resources, providing an effective and quality care.

Key-words: Emergency Medical Services; Heart Arrest; Quality of Health Care.
Submetido: 09/07/2019 Aceito: $18 / 11 / 2019$ 


\section{INTRODUÇÃO}

A parada cardiorrespiratória (PCR) caracterizase pela interrupção súbita da circulação sistêmica e da atividade respiratória, com ausência de pulso e movimentos torácicos inspiratórios efetivos em um indivíduo com expectativa de vida, ou seja, não portador de doença crônica intratável ou em fase terminal. ${ }^{1,2}$

A parada cardíaca súbita é uma das principais causas de morte nos Estados Unidos e um importante problema de saúde pública, com mais de 500.000 mortes de crianças e adultos por ano, sendo que em torno de setenta por cento das PCR fora do hospital ocorrem em casa e aproximadamente $50 \%$ sem que ninguém tenha presenciado. ${ }^{3,4}$

No Brasil, mesmo com avanços nos últimos anos relacionados à prevenção e ao treinamento de manobras de reanimação cardiopulmonar, ainda ocorrem muitos óbitos por PCR, sendo que as doenças cardiovasculares são a principal causa de mortalidade e incapacidade no Brasil e no mundo. A Sociedade Brasileira de Cardiologia estima que ocorrem aproximadamente 200.000 PCR por ano no Brasil, sendo metade dos casos em ambiente hospitalar e a outra metade em ambiente extrahospitalar. ${ }^{5-7}$

$\mathrm{Na}$ atualidade, somente $10,8 \%$ dos pacientes adultos com parada cardíaca não traumática que receberam manobras de reanimação pelo Serviço de Atendimento Médico de Urgência (SAMU) sobreviveram. Porém, este número aumenta significativamente para $25,5 \%$ no ambiente hospitalar. ${ }^{3}$

O procedimento emergencial padrão para assistência do paciente vítima de PCR é denominado reanimação cardiopulmonar (RCP). Segundo a American Heart Association, ${ }^{8}$ a ressuscitação ou reanimação cardiopulmonar é um conjunto de manobras realizadas para promover a circulação de sangue oxigenado no organismo, principalmente em órgãos vitais, na tentativa de manter a vitalidade tissular, até que sejam mantidas as funções ventilatórias e cardíacas espontâneas. ${ }^{2-7}$

As equipes que trabalham com serviços de atendimento a urgências e emergências devem possuir conhecimento dessas manobras, além de serem treinadas, a fim de proporcionar um atendimento de qualidade frente a essas situações. Algumas etapas são essenciais para que a qualidade desse atendimento seja alcançada, sendo elas: identificação da PCR o mais precocemente possível, iniciar o suporte básico e, se necessário, o avançado de vida. ${ }^{2-7}$

Considerando que a eficiência e o resultado satisfatório no atendimento a uma vítima de PCR no ambiente pré-hospitalar dependem de conhecimento técnico-científico, controle do ambiente, habilidades e técnicas interpessoais, além de outros fatores, justificase a realização desse trabalho que visa analisar as publicações com o objetivo de identificar os principais fatores determinantes que interferem na qualidade do atendimento a vítimas de PCR no ambiente préhospitalar.

\section{MATERIAIS E MÉTODOS}

Trata-se de uma revisão bibliográfica que consiste na combinação de dados da literatura teórica e empírica objetivando reunir informações e dados para descrever e caracterizar o objeto de investigação do estudo.

Para elucidação do mesmo, nos apropriamos das etapas descritas por Souza et al $^{9}$ que propõe a identificação do problema, no qual se define a pergunta norteadora e o propósito de revisão associada, os critérios para inclusão dos estudos, as informações a serem coletadas e os resultados relevantes. Ao término desta etapa, iniciou-se a pesquisa bibliográfica onde foram selecionados os estudos de interesse para a questão pesquisada.

Os dados foram coletados à luz de uma investigação criteriosa, norteada pelos critérios de inclusão na pesquisa. Após coletados, os dados, foram tratados, ordenados e categorizados e resumidos para análise. O resultado dos dados analisados proporcionou uma conclusão unificada sobre o problema de pesquisa que serão apresentados em forma de síntese ou análise. ${ }^{9}$

Nesse estudo, buscou-se responder à questão: quais os fatores determinantes na qualidade do atendimento a vítimas de PCR no ambiente préhospitalar? A busca dos estudos foi realizado em julho de 2017, utilizando os seguintes critérios de inclusão: artigos publicados em inglês, espanhol e português, com os textos completos disponíveis na base de dados da Literatura Internacional em Ciências da Saúde (Medline), Índice Bibliográfico Espanhol em Ciências da Saúde (IBECS) e Scientific Eletronic Library Online (Scielo), no site de busca Google Scholar (Google Acadêmico) e Literatura Latino-Americana e do Caribe em Ciências da Saúde (LILACS), no período de 2008 a 2016, utilizando as terminologias em saúde: "serviços médicos de emergência", "parada cardíaca" e "qualidade atendimento" conforme consulta nos Descritores em Ciência da Saúde (DeCS/BIREME).

Para a coleta dos dados foi utilizado um instrumento que auxiliou o percurso metodológico aos executores do estudo, contendo dados relacionados ao pesquisador/autor do estudo, ao artigo e ao objeto do estudo. ${ }^{9} \mathrm{~A}$ busca foi realizada na íntegra, pelo acesso livre online, utilizando como eixo norteador a questão de estudo.

Posteriormente, elaborou-se um quadro sinóptico contendo dados relacionados ao autor, ao ano de publicação do artigo, ao periódico onde foi publicado e as sínteses/análises dos estudos para posterior discussão. 


\section{RESULTADOS E DISCUSSÃO}

A tabela 1 apresenta os resultados
encontrados.
Para análise da qualidade dos periódicos de publicação do grupo amostral, foi utilizado o nível de evidência científica descrito por Whitemore e Kethllen. ${ }^{10}$ O autor refere o nível 1 para evidências resultantes da meta-análise de múltiplos estudos clínicos controlados e randomizados, nível 2 para evidências obtidas em estudos individuais com delineamento experimental, nível 3 para evidências de estudos quase experimentais, nível 4 para evidências de estudos descritivos (não experimentais) ou com abordagem qualitativa, nível 5 para evidências provenientes de relatos de caso ou de experiência e nível 6 para evidências baseadas em opiniões de especialistas. ${ }^{10}$

De acordo com o extrato da produção intelectual por nível de evidência, obteve-se $43 \%$ com nível 5, 36\% com nível 4 e $21 \%$ com nível 3 . Não foram identificados estudos que se enquadravam nas categorias de evidência 1,2 e 6.

A partir da análise do grupo amostral, houve a distribuição por fatores determinantes que interferem na qualidade do atendimento a vítima de PCR em 4 categorias: I- estrutura física, recursos humanos, materiais e equipamentos; II- organização dos procedimentos e agentes estressores; III- sentimentos, emoções e alterações físicas dos profissionais envolvidos; e IV- conhecimento técnico/prático da equipe.

\section{Categoria I: estrutura física, recursos} humanos, materiais e equipamentos

A influência da estrutura física, recursos humanos, materiais e equipamentos no atendimento a PCR foram citados em $50 \%$ dos artigos selecionados para esse estudo. O espaço físico, a distribuição espacial das pessoas e equipamentos podem favorecer ou dificultar o trabalho a ser realizado. ${ }^{11}$

Menezes reafirma a existência desses aspectos e acrescenta a organização do atendimento e insuficiência de recursos humanos, comprometendo o sucesso da reanimação e por consequência, a vida da vítima. ${ }^{12}$

Quanto aos recursos materiais e equipamentos o suprimento ideal deve ser indispensável e devem estar disponíveis em quantidades suficientes a qualquer momento. ${ }^{13}$ Entretanto, a insuficiência ou a não existência desses insumos não deve prorrogar ou interromper o atendimento à PCR, uma vez que o fator tempo é crucial para o restabelecimento da ventilação e circulação espontânea, além de ser determinante no sucesso do atendimento.

Outro trabalho, sobre a validação de um instrumento para avaliação da qualidade da assistência no ambiente pré-hospitalar, enfatiza o armazenamento de equipamentos, materiais e insumos no interior das ambulâncias dos serviços de emergência influenciando negativamente na qualidade do atendimento. ${ }^{14}$

Como o principal objetivo dos serviços de urgência/emergência é diminuir morbimortalidade e as sequelas incapacitantes, para tanto, é necessário garantir elementos necessários em um sistema de atenção de emergências considerando recursos humanos, infraestrutura, equipamento e materiais para assegurar uma assistência integral, com qualidade adequada e contínua. ${ }^{11}$

Dessa forma, com intuito de reduzir a ocorrência de óbitos, tempo de internação e sequelas decorrentes de diversos agravos por atrasos no atendimento precoce, dentre eles, uma PCR, o governo federal estruturou a rede de atendimento às urgências em 2003, através da Portaria n. 2.048/GM que regulamenta a Política Nacional de Urgência e Emergência. ${ }^{15}$ Esta portaria visa adequar os serviços de saúde, principalmente os serviços relacionados ao atendimento pré-hospitalar e de emergências. ${ }^{16,17}$

Tabela 1: Distribuição da população e amostra da pesquisa, segundo base de dados, Belo Horizonte - MG, 2017.

\begin{tabular}{lcccc}
\hline $\begin{array}{c}\text { Base de dados/Portal/ } \\
\text { Biblioteca virtual }\end{array}$ & População & \% & Amostra & \% \\
\hline Google Acadêmico & 1920 & 91.6 & 10 & 71.4 \\
IBECS & 07 & 0.3 & 00 & 0.0 \\
LILACS & 152 & 7.2 & 02 & 14.2 \\
Medline & 13 & 0.6 & 01 & 7.1 \\
Scielo & 04 & 0.2 & 01 & 7.1 \\
\hline TOTAL & 2096 & 100 & 14 & 100 \\
\hline
\end{tabular}


Lima et al. Reanimação cardiopulmonar: fatores determinantes.

Categoria II: organização dos procedimentos e agentes estressores

Nos estudos selecionados, essa temática foi abordada por $35,7 \%$ dos autores. Segundo os mesmos, a organização dos procedimentos e os agentes estressores são fatores que interferem na realização das atividades assistenciais, no dimensionamento insuficiente da cena, na rapidez e eficiência no atendimento. Além disso, esses fatores também podem contribuir para uma despersonalização do atendimento ao paciente e sua família, proporcionando distanciamentos, sofrimentos, tensões e conflitos entre os profissionais. ${ }^{11-18}$

Conova, ${ }^{13}$ Carreno et $\mathrm{al}^{14}$ e Cristina et $\mathrm{al}^{18}$ descrevem os agentes estressores no atendimento à PCR, sendo eles: situação de emergência, temperatura ambiente, esforço físico, falta de conhecimento teórico prático, assim como de habilidades e de gestão.

Filho constatou em sua pesquisa que os principais fatores que influenciam negativamente a qualidade da RCP são: ${ }^{19}$ o elevado número de profissionais e pessoas no cenário, falta de harmonia e estresse de algum membro da equipe, falta de material e/ou falha de equipamento e presença de familiar no início do atendimento. A falta de harmonia retratada por este autor e pelos estudos envolvidos nesta pesquisa está relacionada a desorganização na execução dos procedimentos, principalmente dos procedimentos técnicos. Percebe-se que procedimentos não organizados podem acarretar em cascatas de iatrogenias, além de redução da eficácia da reanimação.

Em outra pesquisa mostrou-se que um dos aspectos mais estressantes do serviço é o atendimento a pacientes fora de uma unidade de saúde, pois trabalhar em via pública gera vários riscos. Segundo o autor, há relatos de que no Reino Unido $2-3 \%$ dos incidentes com profissionais do Atendimento Pré-Hospitalar (APH) foram associados à violência e agressão, de modo que a equipe deve estar preparada para atos violentos e risco de assaltos à mão armada. ${ }^{20}$

Além dos fatores descritos acima, outros autores abordaram isoladamente em seus estudos os seguintes aspectos estressantes: conflitos éticos e morais entre os profissionais atuantes, a comunicação insuficiente, ou mesmo ausência de informações prévias ou transmissão incorreta, ausência de liderança no momento de intervenção na RCP, falta de capacitação e treinamentos permanentes, riscos de assaltos e violência nas vias públicas. ${ }^{11,12,20-22}$

Ainda em três estudos, ${ }^{11,17,23}$ os autores trazem o elevado tempo resposta como fator influenciador. $\mathrm{Na}$ pesquisa de Magalhaes, ${ }^{24}$ sobre os indicadores de qualidade na emergência médica pré-hospitalar traz que o tempo-resposta não pode ser superior a 8 minutos. Sendo, o estimado na capital do estado de Minas Gerais, de nove minutos nos serviços pré-hospitalares. ${ }^{23}$
Categoria III: sentimentos, emoções e alterações físicas dos profissionais envolvidos

O profissional do Serviço de Emergências Médicas (SME), no local de uma emergência, pode ter apenas alguns segundos para avaliar a situação, a condição dos doentes e os recursos, a fim de tomar as decisões e iniciar o atendimento ao doente. ${ }^{14}$

O atendimento pré-hospitalar é visto por muitos profissionais como um serviço desafiante e difícil, os quais se deparam cotidianamente com situações inesperadas, perigosas, ameaçadoras, desconhecidas e angustiantes. Segundo os autores, o ambiente estressante pode ocasionar pânico, confusão, alterações físicas e psicológicas. ${ }^{13-18}$

O estudo mostra ainda que no momento do atendimento em PCR, a equipe demonstra reação como ansiedade, irritabilidade, taquicardia e estresse. Acrescentam ainda como fator dificultador na atuação em RCP as manifestações psicofísicas como tensão na região cervical, rigidez muscular e hipertensão. ${ }^{21}$

Tendo em vista a temática desenvolvida é importante e necessário um suporte psicossocial à equipe que desempenha o trabalho frente a $P C R$, pois o conhecimento acerca dos sentimentos vivenciados propiciará atitudes em seu comportamento em relação não só ao paciente como também ao desenvolvimento de uma prática mais saudável, um atendimento eficaz e de qualidade. ${ }^{18}$

\section{Categoria IV: conhecimento técnico/prático da equipe}

Nos estudos selecionados, 78,5\% citam em suas pesquisas a influência do conhecimento técnico e prático da equipe no atendimento a PCR. Para eles são fatores que implicam as condições relevantes ao sucesso ou insucesso do atendimento pelo serviço de Urgência e Emergência, quem determina o reconhecimento precoce ou tardio da PCR, início precoce ou tardio das compressões, o conhecimento e desconhecimento das novas diretrizes de RCP. ${ }^{12-23}$

$\mathrm{O}$ atendimento a vítima de PCR tem que ser padronizado e realizado com a máxima rapidez e eficiência. Deve existir uma rotina e as responsabilidades de cada profissional envolvido devem ser definidas, pois essa medida aumenta a eficiência do atendimento, proporcionando uma maior sobrevida do paciente. ${ }^{25}$

Por isso as equipes devem estar preparadas tecnicamente e cientificamente para enfrentar o desafio desse evento súbito e grave, tendo a consciência da necessidade de diagnóstico precoce e intervenção efetiva, levando-se em consideração que o prognóstico do cliente está diretamente ligado ao tempo e à eficácia das ações, uma vez que a falta de conhecimento traz como consequência um agir inadequado, com prejuízos 
Lima et al. Reanimação cardiopulmonar: fatores determinantes.

na assistência prestada e a sobrevida. ${ }^{26}$

Sendo assim, para promover uma assistência qualificada e eficaz é necessário o investimento na capacitação e educação continuada das equipes de saúde em todos os âmbitos da atenção à saúde, como enfatiza a Portaria GM/MS n. 2.048/02.15 Além de um trabalho específico no melhoramento dos fatores que influenciam negativamente nesse atendimento de qualidade. ${ }^{15}$

A literatura recomenda que os programas de capacitação devam ser aplicados, preferencialmente, em intervalos não superiores a seis meses e afirma que a fixação do conhecimento teórico e a preservação das habilidades técnicas estão diretamente relacionadas com a experiência e a aplicação na prática. Dessa forma, sugere-se que os cenários dos cursos devem ser os mais próximos possíveis da realidade da situação do atendimento da PCR. ${ }^{22,27}$

As equipes que trabalham com esse serviço devem ser treinadas para realizar a identificação precoce da PCR, iniciando assim o suporte básico e, se necessário, o avançado de vida. Para a aplicação do atendimento avançado eficaz deve-se começar o atendimento básico criterioso e principalmente com realização de RCP de alta qualidade. ${ }^{2,7,13}$

O Suporte Básico de Vida - Basic Life Support (SBV-BLS) tem como principal objetivo proporcionar o atendimento imediato das pessoas em situação de PCR. A sobrevida dessas vítimas está atrelada a organização de um sistema de atendimento emergencial ágil e eficiente. Nesse sentido a AHA estabeleceu a corrente de sobrevivência há mais de duas década, propondo ações concretas que estabelecem e expressam os padrões de atendimento, tendo como objetivo principal não agravar lesões já existentes ou gerar novas lesões.8,28,29

Segundo estudos de Alves, ${ }^{27}$ o profissional que trabalha nos serviços de emergência deve ser ágil, ter raciocínio clínico rápido, além de habilidades técnicas e controle emocional frente a situações crítica. Para Sjoberg, ${ }^{30}$ não são necessárias apenas as características descritas anteriormente e a capacitação dos profissionais frente a uma PCR, é necessário que a equipe tenha capacidade de controlar os fatores causadores do estresse, além de ter harmonia e sincronismo nos procedimentos. Conova acrescenta ainda a eficiência e infraestrutura adequada. ${ }^{12}$

\section{CONCLUSÃO}

Diante dos estudos analisados pôde-se evidenciar os fatores que influenciam negativamente no atendimento à vítima de $\mathrm{PCR}$, tais como: estrutura física inadequada, ambiente estressante, insuficiência de recursos humanos, deficiência e falta de manutenção em materiais e equipamentos, falta de organização para a execução dos procedimentos pela equipe, sentimentos e emoções da equipe e dos profissionais envolvidos, fragilidades no conhecimento técnico/prático da equipe, falta de habilidades para execução e implementação de protocolos de atendimento a PCR.

Dessa forma, os resultados apontaram temas, situações e comportamentos que devem ser trabalhados incessantemente para melhoria e o aprimoramento no atendimento à vítima de PCR no ambiente extrahospitalar.

Sendo assim, a descrição dos principais fatores que influenciam o atendimento de qualidade em uma vítima de PCR no ambiente pré-hospitalar pelos serviços de urgência e emergência no Brasil puderam ser evidenciados, servindo de subsídio na atualização de protocolos assistenciais, identificando a necessidade de educação permanente das equipes, adequação e gerenciamento de recursos humanos e materiais em diversas entidades e empresas.

Como limitação do estudo pode-se constatar a não identificação de estudos caracterizados como meta-análise de múltiplos estudos clínicos controlados e randomizados, além de evidências obtidas em estudos individuais com delineamento experimental. Esses tipos de estudos possuem uma força de evidência elevada que poderiam ter descortinados outros fatores determinantes no atendimento a vítimas de parada cardiorrespiratória pelos serviços pré-hospitalar.

Nesse sentido, faz-se importante investir em estudos que contemplem os delineamentos citados anteriormente com o intuito de analisar, detalhadamente, os atendimentos realizados, viabilizando propostas para o enfrentamento dos problemas identificados.

\section{REFERÊNCIAS}

1. Feitosa Filho GS, Feitosa GF, Guimarães HP, Lopes RD, Júnior RM, Souto FAS et al. Atualização em reanimação cardiovascular: o que mudou com as novas diretrizes. Rev. bras. ter. intensiva. $2006 ; 2(18): 177-85$

2. Timerman S, Gonzalez MMC, Ramires JAF, Quilici AP, Lopes QD, Lopes AC. Ressuscitação no Brasil e no mundo e o ILCOR (Aliança Internacional do Comitê de Ressuscitação): história e consenso 2010 de ressuscitação cardiopulmonar e emergências cardiovasculares. Rev. soc. cardiol. Estado de São Paulo. 2010; 20(2):207-23.

3. Kleinman ME, Brennan EE, Goldberger ZD, Swor RA, Terry M, Bobrow BJ, ET AL. Part 5: adult basic life support and cardiopulmonary resuscitation quality. In: American Heart Association. American Heart Association Guidelines Update for Cardiopulmonary Resuscitation and Emergency Cardiovascular Care. Dallas: Circulation; 2015.

4. Bhanji F, Donoghue AJ, Wolff MS, Flores GE, Halamek LP, Berman JM et al. Part 14: education: resuscitation. Dallas: Circulation; 2015. 
5. Murray CJL, Lopez AD. The Global Burden of Disease: a comprehensive assessment of mortality and disability from disease, injuries and risk factors in 1990 and projected to 2020. Cambridge: World Health Organization, World Bank \& Harvard School of Public Health; 1996.

6. Kawakame P, Miyadahira A. Avaliação do processo ensino aprendizagem de estudantes da área de saúde: manobras de ressuscitação cardiopulmonar. Rev. esc. enferm. USP. 2015; 49(4):657-64.

7. Gonzalez MM, Timerman S, Oliveira RG, Polastri TF, Dallan LAP, Araújo $S$ et al. Guideline for cardiopulmonary resuscitation and emergency cardiovascular care: Brazilian Society of Cardiology: executive summary. Arq Bras Cardiol. 2013.

8. American Heart Association. Destaque das diretrizes da American Heart Association 2010 para RCO e ACE [versão em português]. 18 de outubro de 2010. Disponível em: http:// www.heart.org/idc/groupps/heartpublic/@ecc/documents/ downloadable/ucm_31733.pdf.

9. Sousa MT, Silva MD, Carvalho R. Revisão integrativa: o que é e como fazer. Einstein. 2010; 8(1):102-06.

10. Whitemore $R$, Kethllen $K$. The integrative review: updated methodology. J. Adv. Nurs. 2005; 52(5):546-53.

11. Azevedo ALCS, Chaves LDP. Gerenciamento do cuidado de enfermagem em unidade de urgência traumática [Dissertação]. Ribeirão Preto: Universidade de São Paulo; 2010.

12. Menezes RR, Rocha AKL. Dificuldades enfrentadas pela equipe de enfermagem no atendimento à parada cardiorespiratória. InterScientia. 2013; 1(3):2-15.

13. Conova JCM. Parada cardiorrespiratória e ressuscitação cardiopulmonar: vivências da equipe de enfermagem de um hospital escola [Dissertação]. Ribeirão Preto: Universidade de São Paulo; 2012.

14. Carreno I, Veleda CN, Moreschi C. Característica da equipe de atendimento pré-hospitalar no interior do Rio Grande do Sul. Rev. min. enferm. 2015; 19(1):88-94.

15. Ministério da Saúde (BR). Regulamento técnico dos sistemas estaduais de urgência e emergência. Portaria n. 2.048/GM, de 5 de novembro de 2002. Brasília: Imprensa Nacional; 12 nov. 2002; p. 32-54.

16. Siqueira $\mathrm{HCH}$, Pereira QLC, Eveline do Amor Divino EA. A capacitação da equipe que atua no atendimento pré-hospitalar móvel: necessidade e importância da educação permanente na perspectiva dos trabalhadores. Rev. min. enferm. 2009; 13(3):365-71.

17. Morais DA. Ressuscitação cardiopulmonar pré-hospitalar: fatores que determinantes da sobrevida [dissertação]. Belo Horizonte: Universidade Federal de Minas Gerais; 2012. 113 p.

18. Cristina JA, Dalri MCB, Cyrillo RMZ, Saeki T, Veiga EV. Vivências de uma equipe multiprofissional de atendimento préhospitalar móvel em suporte avançado de vida na assistência ao adulto em situação de parada cardiorrespiratória. Cienc. Enferm. 2008; 14(2):97-105.

19. Filho CMC, Santos ES, Silva RCG, Nogueira LS. Fatores que comprometem a qualidade de ressuscitação cardiopulmonar em unidade de internação: percepção do enfermeiro. Rev. esc. enferm. USP. 2015; 49(6):908-14.

20. Dantas RAN, Torres GV, Salvetti MG, Dantas DV, Mendonça $A E O$. Instrumento para avaliação da qualidade da assistência pré-hospitalar móvel de urgência: validação de conteúdo. Rev. esc. enferm. USP. $2015 ; 49(3): 381-7$.

21. Sa CMS, Souza NVDO, Lisboa MTL, Tavares KFA. Organização do trabalho e seus reflexos na atuação dos trabalhadores de enfermagem em ressuscitação cardiopulmonar. Rev. enferm. UERJ. 2012; 20(1):50-5.

22. Rocha $F A Z$, Oliveira $M C L$, Cavalcante RB, Silva PC, Rates HF. Atuação da equipe de enfermagem frente à parada cardiorrespiratória intrahospitalar. Rev. enferm. Cent-Oeste Min. 2012; 2(1):141-50.

23. Correa AR, Carvalho DV, Morais DA. Características dos atendimentos a vítimas de parada cardiorrespiratória extrahospitalar. Rev. enferm. UFPE on line. 2013; 7(11):6382-90.

24. Magalhães ASC, Boto $P$, Lavinha P. Indicadores de qualidade na emergência médica pré-hospitalar. Painel Operacional para o INEM, I.P. Curso de Especialização em Administração Hospitalar. 2012.

25. Silva MRC. Elaboração de guia teórico de atendimento em parada cardiorrespiratória para enfermeiros. Rev. RENE. 2013; 14(4):1014-21.

26. Cardoso LF. Protocolo institucional: atendimento a parada cardiorrespiratória (PCR). Versão atualizada em 8 de agosto de 2011. São Paulo: Hospital Sirio Libanes; 2011. Disponível em: http://www.hospitalsiriolibanes.org.br/sociedadebeneficentesenhoras/ Documents/protocolos-institucionais/ protocolo-pcr.pdf

27. Alves CA, Barbosa CSS, Faria HTG. Cadiorespiratory arrest and nursing: the knowledge on basic life support. Cogitare enferm. 2013; 18(2):296-301.

28. Luciano PM, Matsuno AK, Moreira RSL, Schmidt A, Pazin Filho A. Suporte básico de vida. Rev. soc. cardiol. Estado de São Paulo. 2010; 20(2):230-8. 
29. American Heart Association. Destaque das diretrizes da American Heart Association 2015 para RCO e ACE [versão em português]. Outubro de 2015. Disponível em: http://www.heart. org/idc/groupps/heartpublic/@ecc/documents/downloadable/ ucm31733.pdf

30. Sjoberg F, Schonning E, Sallzmann-Erikson M. Nurses experiences of performing cardiopulmonar resscitation in intensivce carea units: a qualitative study. J Clin Nurs. 2015; 24(17-18):2522-8. 